\title{
pro.posıções
}

$e$-ISSN 1980-6248

http://dx.doi.org/10.1590/1980-6248-2016-0007

ARTIGOS

\section{Simón Rodríguez y la escucha al borde del vacío: lecturas en clave ontológica de la escuela}

\author{
Simon Rodríguez e a escuta a beira do vazio: leitura em chave \\ ontológica da escola
}

\section{Simón Rodríguez and listening at the edge of emptiness: ontological readings of the school}

Maximiliano Lionel Durán (i)

(i) Universidade do Estado do Rio de Janeiro - UERJ, Rio de Janeiro, FAPERJ, RJ, Brasil. https://orcid.org/0000-0002-7213-6834, maximiliano1771@gmail.com

Resumen: Simón Rodríguez crea, en 1826, una escuela completamente novedosa en la ciudad de Chuquisaca. Por primera vez en América, los niños y las niñas de las distintas castas son incluidos en un mismo salón de clases en calidad de iguales. A lo largo de su obra, Rodríguez hace referencia a esa escuela inédita en el continente americano con el nombre de educación popular. Dicha escuela se caracterizó por el despliegue axiomático de un principio igualitario. A diferencia de otros proyectos escolares latinoamericanos, cuyo objetivo final era generar, en el mejor de los casos, ciertas condiciones de igualdad entre la población escolar, la escuela de Rodríguez parte de la igualdad como su condición de posibilidad. En este trabajo, se intentará pensar un componente particular de la escuela popular: el maestro. Para ello, se dividirá el artículo en tres partes. En la primera, se desarrollará un análisis de las categorías ontológicas y metaontológicas de Alain Badiou. En esa sección del trabajo, se presentarán brevemente las categorías de situación, estado de la situación, vacío y acontecimiento. En la segunda, se expondrá la reapropiación de esas categorías por Alejandro Cerletti. Dicho autor realiza una relectura de las categorías badiouanas en clave educativa. La última parte consistirá en el análisis del concepto de maestro implícito en la escuela popular de Simón Rodríguez, en función de las categorías trabajadas en las dos primeras secciones. Esa sección demostrará que el maestro popular es aquel que acompaña a los niños y a las niñas a través de un proceso de atención centrado en la escucha al borde del vacío.

Palabras clave: Simón Rodríguez, filosofía, educación popular, maestro popular, vacío 


\section{pro.posıções}

$e$-ISSN 1980-6248

http://dx.doi.org/10.1590/1980-6248-2016-0007

Resumo: Simon Rodríguez cria em 1826 uma escola completamente original na cidade de Chuquisaca. Pela primeira vez na América, os meninos e as meninas que compöem as distintas castas são incluidos numa mesma sala de aula em qualidade de iguais. Ao longo de sua obra, Rodríguez faz referência a essa escola inédita no continente americano com o nome de educação popular. A escola criada por Rodriguez se caracteriza pelo desenvolvimento axiomático dum princípio igualitário. A diferença doutros projetos escolares latino-americanos da mesma época cujo propósito é, no melhor dos casos, gerar certas condições de igualdade entre a população escolar, a escola de Rodriguez parte da igualdade como sua condição de possibilidade. Neste trabalho, procura-se pensar um dos componentes dessa escola popular: o professor. Para alcançar o objetivo proposto, dividiu-se o artigo em três partes. Na primeira delas, desenvolveu-se uma análise das categorias ontológicas e metaontológicas do filósofo francês Alain Badiou. Nessa seção, apresentamse brevemente os conceitos de situação, estado da situação, vácuo e acontecimento. Na segunda parte do trabalho, mostra-se a reapropriação dessas categorias por parte de Alejandro Cerletti. O autor realiza uma leitura das categorias badionanas em clave educativa. A última parte se propõe, a partir dessas categorias, fazer uma análise do conceito de professor implícito na escola de Rodríguez, com o propósito de mostrar que o professor popular é aquele que acompanba as crianças num processo de atenção centrado na escuta à borde do vácuo.

Palavras Chaves: Simón Rodríguez, filosofia, educação popular, professor popular, vácuo

Abstract: Simon Rodriguez, created in 1826 a completely new school in the city of Chuquisaca. For the first time in Latin America boys and girls of different castes were included in the same classroom as equals. Throughout his work, Rodriguez refers to this unprecedented school in America under the name of popular education. This school was marked by the deployment of an axiomatic egalitarian principle. Unlike other Latin American school projects whose ultimate goal was, at best, to create certain conditions for equality among the school population, Rodriguez's school regards equality as its condition of possibility.

This paper attempts to think of a particular component of the popular school: the teacher. To do this, the paper is divided in three parts. In the first part, an analysis of the ontological and metaontological categories of Alain Badiou is developed. In this section, the paper briefly discusses the categories of situation, state of affairs, void, and event. In the second part, the reappropriation of these categories by Alejandro Cerletti is presented. This author rereads of Badiou's categories from an educational perspective. The last part of this paper presents the analysis of the concept of teacher implicit in Simon Rodriguez's popular school in accordance with the categories discussed in the first two sections. The purpose of this section is to show that the popular teacher is the one who accompanies children in a process of attention focused on listening at the edge of the void.

Keywords: Simón Rodriguez, philosophy, popular education, popular teacher, void 


\section{pro.posições}

$e$-ISSN 1980-6248

http://dx.doi.org/10.1590/1980-6248-2016-0007

\section{Introducción}

Simón Rodríguez acuña hace más de un siglo y medio su concepto de educación popular. Dicha idea es utilizada por el maestro para dar nombre a su invención más potente y radicalizada: la escuela popular. Esa institución se diferencia significativamente de toda otra escuela conocida hasta ese momento, en la medida que niega y diluye el principio a partir del cual las escuelas, durante la colonia y los primeros años de la república, se constituían. La escuela popular del maestro caraqueño niega el principio de identidad propio de cada una de las instituciones escolares de aquel entonces. El mundo escolar latinoamericano de mediados del siglo XVIII y principios del XIX está compuesto por un cuadro variopinto de instituciones escolares. Cada una de ellas acoge en su interior a un determinado tipo de población, en función de ciertos criterios identitarios establecidos por el sistema de castas.

Margarita Garrido (2007) sostiene que las sociedades coloniales de América tienen una representación del orden en la que la jerarquía étnica corresponde a una jerarquía moral. De acuerdo con el sistema de castas codificado por los Borbones, la élite blanca es el grupo con autoridad para mandar, porque sencillamente es mejor en los aspectos no solo morales, sino también ontológicos. En esa misma línea, Demélas (2003) asegura que las sociedades coloniales están fundadas en una intrincada red de vínculos sociales verticales, que obedecen a una serie de normas tácitas que hacen referencias a los parentescos, al interconocimiento y al respeto por las jerarquías propias de cada grupo (pp. 54-55).

Más allá de la flexibilidad existente en el paso de un grupo a otro dentro de las diversas identidades y de la ambigüedad con las que las autoridades interpretan las definiciones étnicosociales, la autora señala que las jerarquías son un elemento central de la vida andina (p. 64) y no son solo interestamentales, sino también intraestamentales. Cada grupo tiene sus propias jerarquías que hace valer y respetar. En ese contexto, el vínculo entre grupos e individuos está dado a partir de los rasgos identitarios de cada grupo. Es decir, una persona es considerada de acuerdo con su pertenencia estamental.

La fragmentación social, sobre la base de la distinción racial, es un patrón común a través del cual se desarrolla la vida cotidiana dentro de los territorios del imperio español. La miríada de grupos y subgrupos se corresponde palmo a palmo con una serie igualmente numerosa de privilegios y obligaciones. No solo el lugar dentro de las ceremonias públicas equivale al estrato 


\section{pro.posıções}

$e$-ISSN 1980-6248

http://dx.doi.org/10.1590/1980-6248-2016-0007

al que pertenece una persona, sino también la aplicación de la ley y los castigos son diferentes. Por ejemplo, una persona avecinada en el interior de una ciudad del imperio español goza del derecho de no recibir azotes, mientras que un indio, un negro o alguien perteneciente a las castas los sufren.

Las escuelas sostienen, reproducen y conservan ese mundo jerarquizado, estamental, desigual e injusto. De acuerdo con ese estado de cosas, son creadas distintas escuelas, a lo largo y a lo ancho de la colonia, para las castas que componen el imperio: para niños ricos blancos, para niños blancos pobres, para niñas, según su pertenencia estamental y social, para niños de la nobleza de los pueblos originarios, para los hijos de indígenas comunes que no acrediten nobleza de nacimiento, para mestizos y para huérfanos (Garcia Sanchez, 2005; Gonzálbo Aizpurú, 2005; Escobari de Querejazu, 2009, 2012). El ingreso en esas instituciones, así como los contenidos impartidos en cada una de ellas, está determinado y orientado en función de la identidad de la población escolar para la cual son concebidas.

En ese sentido, podríamos decir que el mundo escolar está estructurado sobre la base de un complejo sistema de relaciones estamentales articuladas en torno del principio de identidad. Todas y cada una de ellas exige ese principio como condición de ingreso y aceptación de un alumno. De esa manera, las instituciones educativas garantizan la conservación y la reproducción de un determinado orden social y político, caracterizado por una división jerárquica de las personas que lo componen.

La escuela de Rodríguez rompe con ese mundo escolar, en la medida que no exige principio identitario alguno para recibir a los niños en su interior. El Colegio de Muchachos carpinteros y huérfanos de la ciudad de Chuquisaca recibe en su interior a todos los niños y niñas de la ciudad en calidad de iguales (Vera Peñaranda, 2009). Esa decisión de Rodríguez supone el despliegue de un principio igualitario radical, potente y desconocido hasta ese momento. A igual que todo principio, este se asume como algo del orden de la declaración, de la afirmación y de la derivación de sus consecuencias a partir de su presencia. La igualdad en esa escuela no es algo a ser demostrado o un objetivo a ser alcanzado en algún mundo posible. Es lo que hay, el punto que parte de su propia declaración y de la realidad que se inaugura a partir de sí misma. En otras palabras, la escuela de Chuquisaca afirma la igualdad y experimenta las consecuencias de dicha afirmación en la práctica cotidiana 


\section{pro.posições}

$e$-ISSN 1980-6248

http://dx.doi.org/10.1590/1980-6248-2016-0007

El orden declarativo de la igualdad queda manifiesto no solo a partir de las acciones del educador, sino también por medio de sus escritos. En Sociedades Americanas, él sostiene explícitamente la "escuela para todos porque todos son ciudadanos" (Rodríguez, 1999, p. 326). A diferencia del resto de los proyectos pedagógicos de la época, se afirma que a la escuela ingresan todos porque todos son iguales, todos son ciudadanos, y no a la inversa. La igualdad no es algo que se discute o se prueba argumentativamente. Así escribe Rodríguez:

Que por más que se trabaje en desimpresionar a los pueblos de la idea que tienen formada de su suerte, nada se conseguirá, si no se les hacen sentir los efectos de una mudanza ¿Cómo se hará creer a un hombre, distinguido por ventajas naturales, adquiridas o casuales, que el carece de ellas es su igual? ¿Cómo, por el contrario, creerá otro que nada le falta cuando está viendo que carece de todo? Y ambos ¿Cómo se persuadirán que han pasado a otro estado, si se ven siempre en el mismo? Se discurre, se promete, se hermosean esperanzas... ipero nada de esto se toca! (TI, p. 271)

La afirmación de este principio igualitario muda radicalmente el mundo escolar de su época. Como puede observarse, la escuela de Rodríguez se articula sobre un principio completamente diferente al que rige el resto de las instituciones hasta ese entonces conocidas. Rodríguez no solo niega el principio de identidad afirmado por el resto de las instituciones, sino también determina otro completamente distinto y hasta contradictorio. Las escuelas tradicionales afirman y justifican la desigualdad. De hecho, el principio de identidad exigido para la incorporación de los alumnos a cada una de ellas supone de modo preciso la afirmación de un orden estructurado a partir de la valoración identitaria en el marco de un sistema de castas. Podríamos decir que esas instituciones establecen la desigualdad, mientras que la escuela de Rodríguez subraya su contrario: la igualdad.

La afirmación igualitaria abre las puertas a pensar una escuela diferente a los establecimientos de enseñanza conocidos. Rodríguez (1999) sostiene:

las fundaciones son todas piadosas... - unas para expósitos- otras para huérfanos- otras para niñas nobles- otras para hijos de militares- otras para inválidos... en todas se habla de caridad: no se hicieron por el bien general, sino por la salvación del fundador o por la ostentación del Soberano. (TII, p. 358)

Para él, los saberes de la escuela institucionalizada no sirven para dar cuenta de lo que ocurre en Chuquisaca, precisamente porque su proyecto es algo completamente novedoso para la coyuntura política y social en la que es aplicado. Según sus propias palabras, "el 


\section{pro.posıções \\ $e$-ISSN 1980-6248}

http://dx.doi.org/10.1590/1980-6248-2016-0007

establecimiento que se emprendió en Bolivia es social, su combinación es nueva, en una palabra es la República” (Rodríguez, 1999, p. 358). En ese sentido, educación popular es el nombre a través del cual se conceptualiza el despliegue de un principio igualitario. Es el punto de partida para la creación de una escuela nueva, diferente: la escuela popular.

En trabajos anteriores, pensamos en torno a la escuela popular. Es decir, señalamos algunas características propias de esa escuela (Durán, 2015, 2016). Entre las más destacadas, se encuentran la igualdad, la hospitalidad y la irreverencia. Para nosotros, una escuela popular es aquella en la que se despliega la igualdad como un principio, se ofrece la hospitalidad como un gesto incondicional e incondicionado y se niega toda reverencia, temor y respeto fundados en algún tipo de superioridad. En otras palabras, pensamos que una escuela popular afirma la igualdad para todos y cualquiera sin reconocer temor ni superioridad alguna de nadie sobre nadie. Según nuestro punto de vista, ese tipo de escuela puede estructurarse a partir de la obra de Rodríguez.

En este trabajo, intentamos razonar sobre un componente particular de la escuela popular: el maestro. Para ello, dividimos nuestro trabajo en tres partes. En la primera, desarrollamos un análisis de las categorías ontológicas y metaontológicas de Alain Badiou. En esta sección del trabajo, se presentan brevemente las categorías de situación, estado de la situación, vacio y acontecimiento. En la segunda parte, exponemos la reapropiación de esas categorías por Cerletti (2008). Dicho autor realiza una relectura de las categorías badiuanas en clave educativa. La última parte consiste en el análisis del concepto de maestro implícito en la escuela popular de Simón Rodríguez, en función de las categorías trabajadas en las dos secciones anteriores. Buscamos mostrar que el maestro popular es aquel que acompaña a los niños y a las niñas a través de un proceso de atención centrado en la escucha al borde del vacío.

De acuerdo con nuestro punto de vista, esa forma de realizar la tarea en el aula abre las puertas a la aparición de novedades aleatorias. Estas pueden dar lugar a transformaciones insospechadas de la realidad escolar, que merecen ser exploradas. 


\section{pro.posıções \\ $e$-ISSN 1980-6248}

http://dx.doi.org/10.1590/1980-6248-2016-0007

\section{Algunas consideraciones ontológicas}

Alain Badiou, a diferencia de gran parte de la tradición filosófica occidental, señala que la forma general de lo que hay es la multiplicidad. Esa afirmación, punto arquimédico de la construcción ontológica de su pensamiento, no solo niega la tradicional preeminencia de lo uno sobre lo múltiple, que la metafísica sostuvo a lo largo de su historia, sino también va más allá. La decisión teórica de Badiou (1999) supone nuevas bases para la ontología, pues su propuesta intenta romper de una vez y para siempre con lo que él denomina "el apresamiento metafísico del ser por lo uno" (p. 26). Esa operación teórica se realiza, en su filosofía, a partir de la negación del ser de lo uno. Las primeras líneas del Ser y el acontecimiento recogen esa apuesta teórica. Allí el filósofo escribe: "Estamos en el punto de una decisión, la de romper con los misterios de lo uno y lo múltiple en los que la filosofía nace y desaparece... Decisión cuya única fórmula posible es la siguiente: lo uno no es" (1999, p. 33).

Para Badiou, lo uno, que no es solo, puede ser concebido como una operación, más precisamente como una operación de cuenta que actúa sobre la multiplicidad infinita. Es decir, para él, lo múltiple es el régimen de toda presentación, y lo uno es solo un resultado operatorio que interviene sobre la multiplicidad. O sea, la variedad inicial es recortada por conjuntos, cuyos elementos también son concebidos como multiplicidades. Esos conjuntos son constituidos a través de una ley que cuenta lo que hay, explicitando cada uno de sus componentes. A esa operación que calcula y estructura la multiplicidad infinita Badiou la llama situación. Ella es la articulación de lo múltiple determinado por la cuenta por uno en cuanto ley de ese sistema. Se trata del lugar del tener-lugar para todos los términos de una multiplicidad implicada.

La situación, en el interior de su filosofía, es concebida como una configuración en la que lo múltiple es pensable como anterior solo tras la aplicación de la operación de cuenta de lo uno. En sus propias palabras, "es siempre en el après-coup de la cuenta que la presentación sólo es pensable como múltiple” (Badiou, 1999, p. 34). Lo uno que no es, entonces, resulta ser aquello que obliga a lo múltiple a revelarse y regula su composición estructurada, porque determina la multiplicidad pura en muchos unos. Podemos decir que la cuenta por uno no solo es una operación, sino también un resultado y una ley de la situación. La cuenta por uno es una ley del múltiple que define y ordena lo que hay, en función a un criterio. 


\section{pro.posıções}

$e$-ISSN 1980-6248

http://dx.doi.org/10.1590/1980-6248-2016-0007

Badiou advierte que, en el interior de toda situación, la multiplicidad se encuentra dividida en dos. Por un lado, múltiple es la presentación que se piensa retroactivamente, carente de toda determinación y predicado, de modo que es un múltiple de múltiples. Y, por otro lado, es varia la composición de la cuenta que actúa sobre la multiplicidad diseminada estructurándola en una diversidad de unos. A la primera multiplicidad la denomina inconsistente, y a la segunda la nombra consistente.

La multiplicidad inconsistente es el supuesto anterior a la cuenta, es la afirmación relativa al no ser de lo uno. No obstante, la situación solo envuelve la existencia de lo uno si la cuenta por uno es la ley de toda situación. Eso quiere decir que no hay nada que pueda ser presentado en el interior de una situación sin ser contado por uno. De hecho, "nada es presentable más que como efecto de la estructura, por lo tanto, bajo la forma de lo uno y de su composición en multiplicidades consistentes" (Badiou, 1999 p. 67). De acuerdo con ello, solo es pensable lo uno. La inconsistencia, la multiplicidad absoluta en última instancia, es incomprobable. Todo lo que es presentado en una situación son multiplicidades consistentes. Más allá de la precedencia de la multiplicidad inconsistente, lo que hay en el interior de toda situación es uno.

Como hemos escrito, la cuenta por uno no solo es ley de la estructura, sino también resultado (se cuenta por uno, y lo que hay es uno). Lo uno que se manifiesta supone algo de lo múltiple que no coincide de forma absoluta con el resultado. Hay un resto fantasmal en el que lo múltiple no se encuentra originalmente en la forma de lo uno. La multiplicidad diseminada, entonces, estría excluida de toda presentación y, al mismo tiempo, como sostiene Badiou, estaría incluida "como lo que 'sería' la presentación misma, la presentación en -sí, si fuera pensable lo que la ley no autoriza a pensar: que lo uno no es, que el ser de la consistencia es la inconsistencia" (p. 68). Dicho de otra manera, en la medida que toda situación se encuentra bajo la ley de lo uno, la multiplicidad pura impresentada en la estructura es nada. Antes de la cuenta, lo que hay es nada, ya que todo es contado. Sin embargo, ese ser nada es la condición de posibilidad de toda composición consistente.

El ser de la nada, como forma impresentable, es la distancia sutil entre lo uno como operación y lo uno como resultado, entre la multiplicidad consistente de toda presentación y la inconsistencia pura. Como sostiene Badiou, la nada no es otra cosa que "el nombre de la impresentación en la presentación" (p.70). Es impresentada por la situación, porque no forma parte de ninguno de los términos de esta. Si lo fuera, debería ser contado por uno y formar parte 


\section{pro.posıções}

$e$-ISSN 1980-6248

http://dx.doi.org/10.1590/1980-6248-2016-0007

de la multiplicidad consistente como una nada. Eso es imposible, ya que haría consistente aquello que se asumió como inconsistente. La nada es el nombre de la multiplicidad pura e inconsistente, precisamente aquello que escapa a toda cuenta y determinación por su diseminación múltiple e infinita. Lo que hay entonces es nada en cuanto fantasmático de la inconsistencia y no una nada.

A su vez, ese resto fantasmático es pensable a partir de la idea de lo uno como resultado. Es decir, lo uno como resultado lleva a pensar en la existencia de algo que no es término de la situación (es nada), pero, al mismo tiempo, es la condición de posibilidad de toda operación. De acuerdo con Badiou, eso equivale a decir que la nada es la operación de cuenta que no puede ser contada por ella misma. Es la incapacidad de la cuenta de medir la eficacia de su propia operatoria. En calidad de ley, ella cuenta todo lo que hay en el interior de la estructura, pero no puede contarse a ella misma. De esa manera, sostiene Badiou, hay algo en toda situación que es impresentado por ella misma. Es la multiplicidad pura sobre la que opera la cuenta y que, en la medida que no es contada, se diferencia de sí misma como resultado de la cuenta. Se trata de un indecidible de la presentación que es impresentable por ella misma (Badiou, 1999).

Badiou denomina vacio a ese no uno sustraído a toda cuenta. Dicho concepto es utilizado por el autor para indicar que nada es presentado —ningún término- y que, al mismo tiempo, su designación se hace a través de la referencia estructural pensable (p. 71). El vacío es el nombre de la multiplicidad inconsistente, el régimen de toda operatoria y consistencia de lo uno. En otras palabras, el vacío, para Badiou, es el nombre propio del ser (Badiou, 2002). Badiou decide llamar vacío a la nada.

Podríamos decir que, en su filosofía, vacío y nada se corresponden. La nada, nombre del múltiple puro impresentado por la situación, es concebida como el vacío de toda situación y nombre propio del ser. En ese contexto, el ser, en cuanto tal, solo es concebido como vacío. El vacío carece de toda sustancia y es lo que se sustrae en la presentación; por ello, solo existe como nombre en el interior de toda situación. Es la falla de la cuenta por uno, aquello que no puede ser contado en la operatoria de la cuenta. Es el nombre propio del ser en el interior de toda situación que no permite ser localizado ni estructurado de manera alguna. En virtud de ello, es lo no-uno, como también aquello que no puede ser compuesto de unos y solo puede ser cualificado en el interior de una situación como "el errar de la nada" (p. 71). No está en ningún lugar y, en virtud de su concepción de múltiple puro, está diseminado en todos lados. 


\section{pro.posıções}

$e$-ISSN 1980-6248

http://dx.doi.org/10.1590/1980-6248-2016-0007

El vacío es considerado, entonces, como una suerte de límite que se sustrae a toda cuenta y que está impresentado en toda situación. Ese límite interno que no puede ser abarcado y completado por ningún procedimiento de reconocimiento lleva a una suerte de incertidumbre estructural. Es decir, no hay nada que garantice la eficacia operatoria de la cuenta. Siempre hay algo que permanece invisible a cada estructura situacional, algo que escapa a esa cuenta y que no puede ser estructurado por la ley de cuenta de la circunstancia. Es decir, no hay forma, en el interior de la situación, de comprender, con los recursos que se tiene, lo que no se presenta de sí. Debido a ello, es necesaria una cuenta que actúe sobre la cuenta inicial y que no deje nada por fuera. Esa segunda cuenta, más exhaustiva que la primera, es distinta de esta. Computa a los elementos presentados por la situación de forma diferente. Ya que, de no hacerlo, se trataría de una reduplicación del cálculo inicial y tendría el mismo tipo de problema que ya hemos descripto.

La necesidad de esa segunda cuenta es explicada por Badiou por medio del axioma del conjunto de los subconjuntos. De acuerdo con este, para todo conjunto existente, hay también el conjunto de los subconjuntos del primero. La aplicación de ese axioma nos lleva no solo a la distinción entre un conjunto dado y su conjunto de los subconjuntos, sino también a la consideración de que todo conjunto presentado incluye un segundo conjunto, que vuelve a contar los elementos del primero. Badiou formula el accionar de la segunda cuenta como una estructura metaontológica de la primera. A esa segunda cuenta Badiou la denomina estado de la situación.

El estado de la situación es una segunda cuenta que actúa sobre la primera de una forma diferente. Mientras que la cuenta de la situación calcula por uno los elementos de la estructura, la del estado de la situación numera esos elementos como conjuntos. El objetivo de esa cuenta es realizar un cierre metaestructural para que nada quede por fuera y se evite el riesgo del vacío, peligro desestructurante de toda cuenta. La segunda cuenta, entonces, se propone a contar por uno la operación inicial que no puede ser contada por ella misma en la situación. A través de la operación de la cuenta de la cuenta se propone cerrar la distancia entre la multiplicidad consistente del cómputo por uno de la situación y la presuposición de la multiplicidad inconsistente del vacío (p. 114). Toda parte de la situación es contada por uno, incluso la cuenta inicial. El estado de la situación considera todas las partes de la circunstancia, incluso el conjunto 


\section{pro.posıções}

$e$-ISSN 1980-6248

http://dx.doi.org/10.1590/1980-6248-2016-0007

completo de las multiplicidades consistentes presentadas por esta, entendidas como parte total o integral. Así el efecto uno de la cuenta inicial también es reconocido como uno.

Badiou sostiene que, gracias al accionar del estado de la situación, es posible afirmar que esta lo uno es (p.116). Sin embargo, más allá de su accionar, la cuenta del estado no puede evitar al vacío como subconjunto. En la medida que el vacío se encuentra incluido universalmente en todo conjunto, no hay ningún tipo de operador de cuenta que pueda expulsarlo. Así sostiene Badiou: "el impresentable vacío sutura la situación a la no separación de su estado" (p.120).

Ahora bien, dada esta estructura ontológica y metaontológica, Badiou afirma que es posible encontrarnos con múltiples presentados y representados, con múltiples representados sin ser presentados y, por último, con términos presentados, pero carentes de representación por parte del estado de la situación. Al primero de ellos Badiou lo denomina con el nombre técnico de normal, mientras que a los otros dos los designa con los conceptos de excresencia y singular respectivamente. Para Badiou, ellos son claves en la tipología en las que se da el ser (p. 117).

Existen situaciones particulares en las que los elementos presentados no son representados por la segunda cuenta del estado, es decir, carecen de una "figura metaestructural reconocible de antemano" (Badiou, 1999, p. 117). Cuando eso sucede, estamos frente a una singularidad. El caso en el que a cada figura estructural le corresponde una metaestructural remite a lo que Badiou denomina una situación de normalidad.

La singularidad, por el contrario, es concebida como una coyuntura de anormalidad. En el caso en el que, en el interior de una particularidad, la cuenta inicial no presentara ninguno de sus elementos, no habría nada a ser representado por parte de la segunda cuenta. Lo único que puede percibirse es la propia multiplicidad, pero como algo incomprensible. En ese caso, estamos ante una situación de anormalidad fuerte, caracterizada por Badiou al borde del vacío, pues su composición no existe para la situación en la que ella se da.

En el interior de esas situaciones, la segunda cuenta resulta totalmente inoperante, puesto que no puede representar nada de lo que la constituye. Badiou denomina a esas situaciones sitios de acontecimientos. De acuerdo con las palabras del filósofo, un sitio es "el mínimum concebible del efecto de la estructura; pertenece a la situación pero lo que le pertenece no pertenece a ella" (Badiou, 1999, p. 197). El sitio no determina ni asegura nada, solo es la 


\section{pro.posıções}

$e$-ISSN 1980-6248

http://dx.doi.org/10.1590/1980-6248-2016-0007

condición de que algo ocurra, de un acontecimiento. Eso quiere decir que, en toda situación, existe siempre la posibilidad de una aparición novedosa, imposible de ser tenida en cuenta por ninguna de las dos estructuras. Las apariciones pueden ser tanto un cuerpo como una voz extraña, una idea disruptiva o una acción ajena a todo lo que hay (Cerletti, 2008, p. 60).

Cuando aquello que aparece no es una simple alteración de lo que hay, sino una novedad inédita en el interior de la situación, estamos ante lo que Badiou denomina acontecimiento. Este es una irrupción radical en el interior de una situación que altera y transforma lo que hay. Dadas las características inéditas de los acontecimientos, estos no pueden ser reconducidos a un estado de normalidad, precisamente porque no hay medida desde donde hacerlo. La aparición de un acontecimiento se da siempre en el interior de una situación, pero escapa a toda regla de esta. Podemos decir que todo acontecimiento siempre es una singularidad ubicada en el interior de una situación particular, que la excede y la suplementa, ya que está totalmente desvinculado de las reglas que allí operan.

El acontecimiento es, entonces, la novedad que quiebra la normalidad de la situación, sus saberes y sus prácticas. Nombra lo no sabido de la circunstancia, porque ninguno de los saberes existentes en la interioridad de estalo alcanza para definirlo. Se trata de una aparición supernumeraria que transforma lo que hay, en la medida que pone en juego algo impredecible, original e ininteligible a partir de los recursos existentes.

\section{Lecturas de una ontología escolar}

La institución escolar entendida como estructura se adecúa a las cuentas ontológicas analizadas en el apartado anterior. De acuerdo con ello, la escuela es entendida como una estructura compleja de repetición compuesta por una doble ley de cuenta (Cerletti, 2008). La primera calcula sus elementos constitutivos: quien enseña, quien aprende, lo que es enseñado y lo que es aprendido. A esa primera cuenta Alejandro Cerletti la denomina situación educativa. De la misma forma que toda situación, la educativa presenta todos los elementos que la constituyen, impresenta el vacío constitutivo de la cuenta y exige una segunda cuenta. Esta será denominada estado de la educación educativa. 


\section{pro.posıções}

$e$-ISSN 1980-6248

http://dx.doi.org/10.1590/1980-6248-2016-0007

Tal cuenta representa aquello que el cómputo inicial presenta. El estado de esa coyuntura educativa es, entonces, la metaestructura de la situación, pues es una cuenta aplicada sobre la inicial. Ella pretende no dejar nada por fuera, incluye no solo los elementos presentados de la situación, sino también lo que escapa a la primera determinación. Para Cerletti (2008), la segunda cuenta define el carácter institucional de la educación, puesto que organiza, define y ordena la situación educativa desde una normativa específica y constituyente (p.39). Esto es, los elementos presentados por la situación educativa son representados por el estado de la circunstancia a través de una serie de rasgos constitutivos del ámbito específicamente escolar.

A diferencia de la primera ley, que enumera los elementos de la situación como individuos, la segunda lo hace a partir de una serie de características que le permiten agruparlos en segmentos propios del mundo escolar. Los calcula de otra forma. Por ejemplo, quien aprende, el alumno presentado por la situación educativa, es considerado a partir de una serie de representaciones que lo incluyen en la estructura situacional de una manera determinada. Así, tras la aplicación de ambas cuentas, podemos encontrarnos con la posibilidad de nombrar alumnos buenos, malos, promedio, repetidores, problemas, etc. Esa segunda cuenta tiene que ver con la forma en la que son incluidos los elementos constitutivos de la situación, define el sentido institucional de la escuela y reasegura que un estado de cosas se mantenga. Es decir, la segunda ley de cuenta en la representación de la presentación se propone garantizar que el vacío de la situación no produzca efectos desestructurantes que alteren la unidad y el normal funcionamiento de la institución.

Ahora bien, Cerletti (2008) sostiene que la distancia entre la situación y el estado de la situación educativa es imposible de determinar definitivamente, ya que la situación se modifica permanentemente. Debido a ello, señala que existe siempre "la posibilidad de que la institución sea desbordada por lo real de la situación" (p. 41). Dicho en otros términos, la imposibilidad de fijar la distancia entre aquello que es presentado y el modo cómo es representado deja abierta la posibilidad de la aparición de una novedad en el interior de la institución escolar, de allí que la unidad y la normalidad que la segunda cuenta se propone asegurar sea inestable. Siempre existe la posibilidad de que una novedad pueda irrumpir, alterar y transformar esa compleja estructura de repetición que constituye la institución escolar. Independientemente de los medios utilizados por la estructura para asegurar la continuidad de un estado de cosas existe siempre la posibilidad 


\section{pro.posições}

$e$-ISSN 1980-6248

http://dx.doi.org/10.1590/1980-6248-2016-0007

de que aparezca una novedad que no pueda ser representada y ponga en crisis la totalidad de la estructura. Cuando ello ocurre, estamos ante la presencia de un acontecimiento.

$\mathrm{Al}$ igual que cualquier otra estructura de repetición, las situaciones educativas siempre están expuestas a la irrupción de lo fortuito. Es decir, más allá de los diversos medios a través de los cuales la estructura pretende garantizarse el control absoluto de lo que ocurre en ella, siempre está abierta la posibilidad de la aparición de una novedad irreductible a lo que hay. Esta dimensión sin control de la estructura en la educación institucionalizada intenta, sin éxito, ser controlada a través de una segunda cuenta metaestructurante. Cómo hemos visto, el Estado intenta sobredeterminar la relación inicial por medio de una serie de representaciones, cuyo único fin es mantener lo que hay como está, o sea, modificado paulatinamente y reabsorbido con los saberes previos. Sin embargo, como ya hemos afirmado, la segunda cuenta también falla en su intento de controlarlo todo. Hay una dimensión fortuita que es constitutiva de toda situación, escapa siempre a la cuenta y se presenta como una amenaza indisoluble de transformación de toda estructura.

Que la educación institucionalizada sea un sitio de acontecimiento, no es garantía de que algo nuevo pueda darse. La aparición de una singularidad puede alterar momentáneamente una situación sin llegar a desestructurarla. Es posible que sea reacomodada a partir de los recursos existentes y todo continúe con normalidad. Podemos decir, siguiendo a Cerletti (2008), que, a partir de una serie de modificaciones realizadas desde los saberes y las prácticas de la situación y de su estado, se puede garantizar momentáneamente "una continuidad en las mismas condiciones en que se daba anteriormente" (p. 66). Para que una novedad sea considerada un acontecimiento, no solo debe ser algo que cuestione y transforme una situación de modo momentáneo, sino fundamentalmente debe generar efectos. Eso es muy difícil en el campo educativo, es más, es casi imposible. Los casos en los que se ha dado algún acontecimiento en el interior de la educación institucionalizada son casi nulos a lo largo de la historia. No obstante, para nosotros, la escuela de primeras letras en la ciudad de Chuquisaca, en 1826, puede ser considerada como un sitio en lo cual irrumpe una novedad potente y radical. Esta no puede ser obturada por el Estado, y sus efectos aun hoy pueden sentirse.

En el caso particular de la escuela de Chuquisaca, la inclusión de niños y niñas de las distintas castas implicó, de acuerdo con las categorías que hemos descrito, un acontecimiento político en la educación. La decisión de crear una escuela en la que la igualdad se constituyó 


\section{pro.posições}

$e$-ISSN 1980-6248

http://dx.doi.org/10.1590/1980-6248-2016-0007

como el punto de partida de la institución implicó un quiebre de las lógicas escolares de la época. La escuela popular de Rodríguez irrumpió como un espacio novedoso e incomprensible desde los saberes escolares de la época. En las próximas líneas, nos interesará pensar el rol del maestro en el interior de estas escuelas. Para ello, analizaremos el concepto de maestro expresado por Rodríguez y lo relacionaremos con las categorías ontológicas aquí expresadas.

\section{El maestro popular}

Walter Kohan (2014) relata una pintoresca anécdota acerca del encuentro entre Rodríguez y un niño jamaiquino llamado Thomas. Ese encuentro marca definitivamente a Rodríguez. De acuerdo con la historia, el educador pierde su sombrero en uno de los balcones de la ciudad de Kingston, mientras jugaba con un grupo de niños. Tras la pérdida del sombrero intentan recuperarlo sin mucho éxito. Se ensayan varias soluciones, pero ninguna funciona. Finalmente la respuesta llega del lugar menos esperado. Un niñito negro, Thomas, que estuvo observando la situación todo el tiempo, propone formar una escalera humana para recoger el sombrero colgado en el balcón. Tras hacer caso de la sugerencia, consiguen recuperar el sombrero y continuar el juego.

Ese simple hecho, en apariencia trivial, tiene para Rodríguez una importancia fundamental (p. 34). De vuelta en la pensión, el maestro reconstruye la situación, se pregunta, piensa. La solución no llegó de él, el maestro, el hombre letrado, sino de un pequeño negro. El diferente, el que ocupa el lugar más bajo dentro del sistema de castas, resuelve el problema. Justamente el excluido de la escuela colonial, por su condición de negro, inventa el camino para conseguir el sombrero perdido. El niño le enseña a Rodríguez que los socialmente excluidos también pueden inventar y jugar como iguales. Solo bastan la decisión y el coraje de llevarlo adelante en una institución educativa. Thomas es el punto de partida de un pensamiento nuevo, que lleva a Rodríguez a meditar sobre sus propias invenciones. El encuentro con el pequeño ayuda al maestro a encontrarse, a ser quien es y todavía no sabía. El niño hace vivir a Rodríguez la idea de una forma diferente de magisterio, una forma que Rodríguez desarrolla germinalmente en sus escritos: maestro es quien ayuda al otro a ser quien es (Kohan, 2014, p. 83). Esa idea puede rastrearse en el interior de sus escritos, principalmente en aquellos que hace mención al concepto de ciudadano. 


\section{pro.posıções}

$e$-ISSN 1980-6248

http://dx.doi.org/10.1590/1980-6248-2016-0007

La mayoría de los proyectos educativos latinoamericanos se proponen la formación de ciudadanos funcionales a las oligarquías criollas, que se quedaron con el poder tras las guerras de emancipación. En la base de esos proyectos, se asumen los individuos carentes de ciertas condiciones y virtudes políticas, sociales, intelectuales y morales. La escuela es la encargada de proporcionar todas ellas en el interior de un espacio sociopolíticamente regulado. De acuerdo con esa visión, el niño que entra a la escuela es concebido como alguien disminuido, incompleto, con necesidad de ser formado para la vida social y política. Los proyectos de educativos de América Latina producidos durante todo el siglo XIX y principios del XX parten de esa idea y conciben la institución escolar como una maquinaria estatal de producción de ciudadanía. Esa forma de lo escolar supone, como podemos observar, que la ciudadanía es algo a ser adquirido, algo que solo puede poseerse tras el proceso educativo que pone en marcha la escuela. Los niños no entran necesariamente a la escuela como ciudadanos. En sentido estricto, ingresarían a ese espacio para hacerse ciudadanos. El proceso formativo consiste en llegar a ser, a su final, algo que no se era en el inicio.

El proyecto de Rodríguez (1999, TI) es completamente diferente, en la medida que la escuela supone que el alumno aprenda a ser quien ya es. Eso se ve con claridad en la afirmación "escuela para todos porque todos son ciudadanos" (p. 324). El proyecto de educación popular sostiene que los niños son ciudadanos desde su ingreso a la escuela y allí aprenden a ser ciudadanos. La obra de Rodríguez está llena de alusiones a la ciudadanía que se aprende siendo (1999, TI, p. 284; 1999, TII), nada de disminución, de falta o de incompetencia. Ellos son y, en la escuela, aprenden a ser quienes son, a encontrarse con ellos mismos. Rodríguez se propone llevar el otro a un encuentro consigo mismo (Kohan, 2014, p. 83).

Ahora bien, ese trabajo de ayudar al otro a ser quien es Rodríguez lo concreta a través de un ejercicio de cuidado con los alumnos. Walter Kohan explora la dimensión de la atención del alumno en El maestro inventor (2014). Allí se muestra el ejercicio que Rodríguez realiza sobre la atención del alumno. Se realza la intención del maestro en captar y llamar la atención de los alumnos. Según el autor, el maestro es aquel "que debe ir en busca de la atención de sus estudiantes, salir al encuentro de esta atención para seducirla, inquietarla e invitarla a que se repose sobre lo que es preciso cuestionar, entender, pensar e inventar" (p. 89). El maestro trabaja con el alumno a partir de un ejercicio constante de atención compuesto por ambos. No se trata de un simple estímulo y desarrollo de un aspecto del alumno, sino que es un juego en el que él 


\section{pro.posıções}

$e$-ISSN 1980-6248

http://dx.doi.org/10.1590/1980-6248-2016-0007

y el maestro entran en contacto a través una relación de atención. El maestro busca la atención del niño porque se encuentra atento a su alumno.

La atención del maestro es trabajada por Rodríguez en toda su obra. Desde su primer escrito hasta el último, podemos encontrarnos con ese tema. De acuerdo con su punto de vista, la atención es un elemento central en la adquisición de las primeras letras (Rodríguez, 1999, TI, p. 203). Para él, un verdadero maestro debe estar atento a su alumno y a su trabajo. La atención evita que la escuela se transforme en un espacio meramente especulativo o de caridad en el que los niños son arrojados para aumentar su ignorancia (p. 227). A través de ella, el maestro abre un espacio educativo en el que se puede "pronunciar, articular y acentuar palabras, fijar su significación, darles el énfasis que pide el sentido, dar a la idea su expresión propia, notar la cantidad, el tono y las figuras de construcción” (p. 237). En otras palabras, la atención se encuentra presente en todo el proceso de enseñanza y aprendizaje.

Para nosotros, ese proceso de atención se apoya fundamentalmente en la escucha. Jean Luc Nancy (2015) plantea una serie de preguntas inquietantes en torno a la filosofía y la escucha. Según su punto de vista, existe una tensión entre ambas, basada en la subsunción de la escucha, por parte de la filosofía, al entendimiento ${ }^{1}$. En función de ello, el autor se interroga si, a lo largo de la historia de la filosofía, el filósofo es el que entiende, pero no escucha. Es decir es "quien neutraliza en sí mismo la escucha para poder filosofar" (p. 11). Ese gesto, de acuerdo con su perspectiva, conduce a una suerte de inadecuación constante entre escucha y entendimiento, entre un sentido (escucha) y una verdad (entendimiento) que parecen autoexcluirse, pero, al mismo tiempo, no puede prescindirse uno del otro, ambos se requieren constantemente (p. 12).

Muy distinto es el caso de la visión en la que existe un isomorfismo entre la imagen y el concepto. De hecho, la forma implícita en la idea de isomorfismo se concibe desde un comienzo, apelando al orden de lo visual. La historia de la filosofía es una muestra clara de ello. Desde Platón y Aristóteles, hay una convivencia mucho más próxima entre la visión y el concepto, entre la imagen, la contemplación y la filosofía que entre ella misma y la escucha. Nancy toma el caso particular de la fenomenología para explicar esta cuestión. Desde su perspectiva, de Kant hasta Heidegger, la filosofía se concentró en la aparición, la manifestación del ser en la que el estudio y el saber filosófico se apoyan en imágenes propias de lo visible más que de lo audible. Sin

\footnotetext{
${ }^{1}$ En francés, el verbo entendre se encuentra vinculado tanto con el entender como con el escuchar.
} 


\section{pro.posıções}

$e$-ISSN 1980-6248

http://dx.doi.org/10.1590/1980-6248-2016-0007

embargo, habría una dimensión propia de lo audible expresada en conceptos como resonancia, eco, acento, tono, sentido, que, a pesar de ser desatendidos por la filosofía, poseen una potencia inusitada para esta.

En lo sonoro, la forma es arrebatada, pero no disuelta. Lo sonoro, sostiene Nancy, produce una vibración, una amplitud y una densidad de la forma a la que la visión solo puede aproximarse. Lo audible, pese a no ser un modelo privilegiado como el anterior por la filosofía, tiene una serie de características que deberían ser atendidas. En el mismo caso de la fenomenología, asegura el autor, la verdad misma del fenómeno es entendida como "aparecer distinguido con la mayor exactitud posible de todo ente ya aparecido y, por consiguiente, también en cuanto desaparecer" (p.14). Si la verdad se constituye como transitividad y transición incesante de un arribar y un partir, se pregunta por qué debería esta verse más que escucharse, sobre todo cuando esta ya no es la verdad identificable y evidente, sino la resonancia de esta, "el eco de la figura en la profundidad abierta" (p. 14).

De acuerdo con eso, Nancy se propone volcar su atención hacia la escucha, mudar de una perspectiva tradicional y hegemónica a otra periférica y no tan atendida por la historia de la filosofía occidental. Por ello, escribe: "queremos aquí aguzar el oído [cursivas en el original] filosófico: dar al filósofo un tirón de orejas para tenderlas hacia lo que siempre interpeló o representó menos al saber filosófico" (p. 13). Esa orientación del oído filosófico sobre la cual escribe Nancy se estructura a partir de un abordaje particular del problema de lo audible en torno a interrogantes tales como: ¿qué seria estar a la escucha?, ¿qué podría significar existir según la escucha, por ella y para ella? y ¿qué elementos de la experiencia y de la verdad se ponen en juego allí? (p. 16). Para el autor, el núcleo de sentidos implícitos en el verbo escuchar constituyen elementos base para resolver esos interrogantes. A partir de un análisis escueto de la etimología de ese verbo desde de su forma latina auscultare, se distingue la existencia de una combinación doble entre la utilización de un órgano sensorial particular, como el oído (auris), y una tensión volcada a la atención de quien escucha e intenta comprender un mensaje derivado de la segunda parte del término. Dicha combinación, como podemos observar, contiene una naturaleza simple (órgano sensorial) y su estado tenso y atento que se expresa en el par oírescuchar (p. 17).

Para Nancy, esa combinación en particular guarda una relación con el intelecto, puesto que supone siempre la intención de entender y comprender un mensaje, un decir. En todo 


\section{pro.posições}

$e$-ISSN 1980-6248

http://dx.doi.org/10.1590/1980-6248-2016-0007

mensaje, en todo discurso, está supuesta la posibilidad de comprensión, de atención y de escucha del sentido. Escuchar un bombo en una marcha política, un silbato en la calle o en un estadio de fútbol parte de la comprensión posible de una situación o de un contexto específico. Escuchar es, de alguna manera, orientarse al acceso de un posible sentido. Es estar tendido a la pesca de un sentido o de una cadena de sentidos que no necesariamente sean evidentes.

Nancy utiliza, para ilustrar eso, una anécdota de la infancia de Stravinski. De acuerdo con ella, el pequeño escuchaba a un campesino mudo hacer unos sonidos muy particulares con su brazo e intentaba imitarlos de la mejor manera posible. El niño, con su esfuerzo, procuraba producir el sonido que oía y, en ese intento, se colocaba en el interior de una cadena de sentido distinta, novedosa. Es decir, hay un intento de comprensión, un colocarse en situación a partir de un contexto determinado, aunque el sentido mismo que inauguraba ese sonido no fuese inmediatamente accesible al niño. Se trata, en palabras de Nancy, de la búsqueda de otra voz "más o menos vocal que de la boca, de otro sonido para otro sentido, distinto del que se habla. Un sentido en los límites o los bordes del sentido" (p. 20). El sonido se presenta no solo como fenómeno acústico, sino también como aquello que, a través de la escucha, es recibido y escrutado por sí mismo, y constituye ese borde, ese margen de sentido hacia el cual estamos tendidos. Estar a la escucha, entonces, es estar tendido al borde del sentido, en sus márgenes, en las orillas de una exterioridad accesible de forma mediata

Para nosotros, las ideas de límite y borde son muy fecundas. Establecer relaciones entre ellas y la escucha abre la posibilidad de pensar nuevos caminos dentro del aula para la construcción de otros sentidos a los establecidos. Nos interesa pensar la potencia de aparición y la creación de algo distinto a lo establecido a partir de esas ideas. Sin embargo, para nosotros, el borde o límite no se sitúa en el sonido, tal como lo señala Nancy. En función de los propósitos que perseguimos en este trabajo, tomamos la decisión teórica de postular y explorar al vacío como concepto de límite de lo que hay y de lo que puede haber. Apoyados en la filosofía de Alain Badiou, sostenemos una idea ontológica del vacío entendido como nombre propio del ser, punto límite y borde de toda posible novedad. De esa manera, escuchar es estar al borde del vacío, de un vacío ontológico impresentado por toda situación.

En el caso de la escuela, la escucha al borde del vacío tiene que ver con la dirección de la atención a lo no dicho, a lo silenciado, a la multiplicidad inconsistente, fuente de toda determinación y consistencia. Es orientar la escucha hacia aquello que permite la posible 


\section{pro.posıções}

$e$-ISSN 1980-6248

irrupción de una novedad. El maestro popular que muestra Rodríguez a lo largo de su obra pareciera ser aquel que ayuda a sus alumnos a ser quienes son por medio de un proceso de atención centrada en la escucha, pero una escucha al borde del vacío. El maestro popular no se propone transmitir un saber dado y verificable. Se dispone y orienta su escucha a lo novedoso, a lo no dicho, a lo invisible, y, en función de ello, organiza los saberes.

\section{Conclusión}

Luis Ángel Castello y Claudia Marsico (2007) señalan que la designación “maestro" es un derivado de la palabra latina magister, formado a partir de magister-os. De acuerdo con los autores, el significado de dicha palabra surge del análisis de los términos que la componen: el adverbio de cantidad magis y el sufijo tero, cuya función es marcar la oposición entre dos términos. En ese sentido, sostienen que el magister es "el mejor" o "el que más sabe” (p. 63). También afirman que, por extensión, esa acepción pasa a ser entendida como "jefe", con una extensión muy vasta en distintos ámbitos: civil, político, religioso y escolar.

El maestro, entonces, es alguien definido por una cierta cualidad, en función de un saber que le proporciona una autoridad frente a los otros. Eso puede verse claramente en el ámbito educativo. Marco Fabio Quintiliano, en sus Instituciones Oratorias (1887), reviste al maestro de una autoridad excepcional frente a sus alumnos, en virtud de sus conocimientos y tareas. En el capítulo II del libro segundo, sostiene que la autoridad de los maestros es similar a la de los padres, en función del saber, del trabajo y de la responsabilidad que deben ser asumidos (p. 70). La relación entre autoridad y saber del maestro es expresada por Quintiliano en una frase en la que se describe la actitud que los alumnos deben asumir frente al maestro en la clase. El autor declara: "Tanto el que oye, tanto como el que declama, deben mirar al maestro, para conocer lo que él aprueba o desaprueba” (p. 71).

Esa misma relación es destacada por numerosos pensadores a lo largo de la historia occidental. Juan Luis Vives, en sus Diálogos (1817) y en el Tratado de la Enseñanza (1984), elogia la sabiduría y la autoridad del maestro de escuela. Comenio (1998), por su parte, en Didáctica magna, realiza aportes similares. Para este autor, el maestro es el formador de la juventud que, con su saber y autoridad, reemplaza a los padres (p. 20). Se trata de una persona que, con su saber y conducta, educa a los niños en el interior de la fe cristiana. Así argumenta: 


\section{pro.posıções}

$e$-ISSN 1980-6248

mayor importancia tiene la consideración que anteriormente hicimos de que en las escuelas cristianas deben formarse ciudadanos para el cielo, no para el mundo; y, por tanto, hay que procurarlos Maestros que inculquen más lo celestial que lo terreno, más lo santo que lo profano. (p.105)

El maestro es aquel que, por su piedad, sus conocimientos y su autoridad, prepara a los niños para una vida cristiana.

Por su parte, Rousseau (1966), en Emilio, y Locke (2012), en Pensamientos sobre la educación, tienen impresiones similares respecto del lugar, del saber y de la autoridad del maestro. Para ambos pensadores, el maestro es una persona que encarna la autoridad paterna, ya sea por ausencia efectiva del padre o por delegación por falta de tiempo. Esa autoridad es cedida en función de las cualidades del maestro. Tanto para Rousseau como para Locke, el maestro es una persona que posee sólidos conocimientos y una moral intachable. Esos conocimientos y cualidades le dan una autoridad sobre el niño, la cual sirve para formarlo adecuadamente.

Como podemos observar, para esos autores, al igual que para el resto de los pensadores aquí citados, el maestro es una persona destacada por su saber y por su autoridad respecto del alumno. Todos ellos señalan la excelencia de la tarea a emprender, las cualidades del maestro en relación al mérito de esa tarea, el saber poseído por él y la autoridad que este detenta. A pesar de estas similitudes, somos conscientes de que existen marcadas diferencias entre los autores a la hora de definir qué es un maestro. También reconocemos que el concepto de maestro construido por cada uno de ellos no se limita a lo que aquí hemos subrayado.

Más allá de las distinciones entre cada uno de ellos, no podemos dejar de ver ese elemento común en todos los escritos. Según nuestro punto de vista, ello podría deberse a que los autores citados comparten una misma tradición de pensamiento. Es decir, todos se forman y producen conceptos en el interior de la tradición occidental europea, aquella que reclama sus orígenes en el mundo grecolatino. Podríamos decir que el concepto de maestro trabajado por los autores mencionados en este trabajo, en alguna medida, recoge a los sentidos y a los significados originales de la palabra y se hace eco de estos. En todos ellos, es posible distinguir la presencia etimológica de la palabra maestro tal como lo hemos escrito al inicio de esta sección del trabajo.

De acuerdo con lo escrito, el maestro popular no puede ser considerado de la misma forma que el maestro tradicional. A diferencia de este, el maestro pensado por Rodríguez no se 


\section{pro.posições}

$e$-ISSN 1980-6248

http://dx.doi.org/10.1590/1980-6248-2016-0007

apoya en una autoridad que se basa en el producto de un saber. Como hemos visto, el maestro se constituye como tal a partir de dirigir su atención y escucha a los bordes de lo aún no dicho, de lo invisible, en busca de captar la aparición de una novedad. En el caso de Rodríguez, el maestro popular es quien escuchó la presencia de aquellos que hasta ese momento no eran tenidos en cuenta, por el saber pedagógico, como iguales. Allí él vio, sintió y escuchó voces que, en el interior de la situación educativa de la época, eran ignoradas y hacia ellas dirigió su atención. Ese proceso de escucha generó la posibilidad de una nueva escuela y de nuevas conceptualizaciones.

La escucha al borde del vacío, hoy en día, es la posibilidad que tiene todo maestro de cambiar la realidad en la que trabaja y de transformarse a sí mismo en un profesional diferente del que la tradición sostiene. Es la oportunidad de huir del saber y de la autoridad instituida para dar lugar a una eventual novedad.

\section{Referencias}

Badiou, A. (1999). El sery el acontecimiento. Buenos Aires: Manantial.

Castello, L. A., \& Marsico, C. (2007). Oculto nas palavras. Dicionário etimológico para ensinar e aprender. Belo Horizonte: Autêntica.

Cerletti, A. (2008). Repetición, novedad y sujeto en la educación. Buenos Aires: Del Estante.

Comenio, J.A. (1998). Didáctica magna. México: Porrúa.

Demélas, M.-D. (2003). La invención politica. Bolivia, Ecuador, Perú en el siglo XIX. Lima: Instituto Francés de Estudios Andino, Instituto de Estudios Peruanos.

Durán, M. (2015). Simon Rodríguez: educación popular y la invención de la escuela popular. Revista da FAEEBA Educação e Contemporaneidade, 24(43), 25-36.

Durán, M. (2016). Simon Rodríguez: Una filosofía de la radical novedad. Caracas: Ediciones del Solar.

Escobari de Querejazu, L. (2009). Historia de la alfabetización en Bolivia. Época colonial s. XVI- XVIII. Estudios Bolivianos, 15, 227-283.

Escobari de Querejazu, L. (2012). Cacique, yanaconas y extravagantes. Sociedad y educación colonial en Charcas s. XVI-XVIII. La Paz: Plural Editores. 


\section{pro.posições}

$e$-ISSN 1980-6248

http://dx.doi.org/10.1590/1980-6248-2016-0007

García Sanchez, Y. (2005). La educación Colonial en la Nueva Granada: entre lo doméstico y lo público. Revista de Historia de la Educación Latinoamericana, 7, 219-240.

Garrido, M. (2007). Libres de todos los colores en Nueva Granada: Identidad y obediencia antes de la Independencia. En C. Aljivín de Losada, \& N. Cristobal (Eds.), Cultura politica en los Andes (1750 - 1950). Lima: IFEA - UNMSM.

Gonzalbo, A. P. (2005). Historia de la Educación en la Época Colonial. La educación de los criollos y la vida Urbana. México: Colegio de México.

Kohan, W. (2014). El maestro inventor: Simón Rodriguez. Buenos Aires: Miño y Dávila.

Locke, J. (2012). Pensamientos sobre la educación. Madrid: Akal.

Nancy, J. L. (2015). Estar a la escucha. Buenos Aires: Amorrortu Editores

Quintiliano, M. F. (1887). Instituciones Oratorias. Madrid: Librería de la Viuda de Hernando y Cía.

Rodríguez, S. (1999). Obras Completas (Vol. I y II). Caracas: Ediciones de la Presidencia de la República Bolivariana de Venezuela.

Rousseau, J.J. (1966). Emile ou de l'éducation. Paris: Garnier - Flammarion.

Vera Peñaranda, P. E. (2009). Simón Rodríguezy sus ideas de educación popular en Bolivia. La Paz: IEB, Inst. Estudios Bolivianos.

Vives, J. L. (1817). Diálogos. Madrid: Edición La viuda de Barco López

Vives, J. L. (1984). Tratado de la enseñanza. México: Porrúa.

Submetido à avaliação em 31 de janeiro de 2016; aceito para publicação em 02 de maio de 2017.

Sometido a evaluación el 31 de enero de 2016; acepto para publicación el 2 de mayo de 2017. 